\title{
Consequências biológicas
}

\section{da utilização de ligas metálicas em medicina dentária}

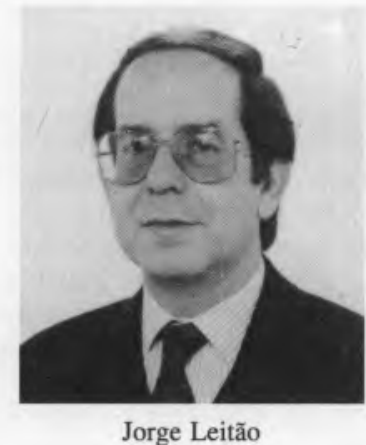

- Professor Associado da Escola Superior de Medicina Dentária de Lisboa (ESMDL). Área de Materiais Dentários. - Licenciado em Medicina, Universidade de Lisboa (1965). - Internato Hospitalar, H. S. Maria (1965).

- Especialista em Estomatologia (1969).

- Professor Auxiliar da Escola Superior de Medicina Dentária de Lisboa (ESMDL) e encarregado da regência da disciplina de Materiais Dentários desde 1978.

- Membro da Comissão Instaladora da ESMDL.

- Especialização em Materiais Dentários, no Departamento de Tecnologia e Biomateriais da Universidade de Bergen, onde estagiou como bolseiro do Governo Norueguês (NORAD) nos anos de 1978, 79, 80, 81, 82 e 83.

- Estagiou ainda no Instituto Escandinavo de Normalização de Materiais Dentários (NIOM).

- É membro das seguintes sociedades científicas:

Sociedade Portuguesa de Estomatologia e Medicina Dentária;

Sociedade Portuguesa de Materiais;

Sociedade Portuguesa de Engenharia Biomédica;

Association Stomatologique International (ASI);

International College of Dentists (ICD);

Academy of Dental Materials (ADAS).
As ligas metálicas à base de metais nobres, ouro, platina e paládio têm sido usadas com sucesso clínico na execução de próteses dentárias desde há longos anos. A partir dos anos 70 e na sequência da subida mundial da cotação do ouro, sucederam-se os ensaios de ligas alternativas à base de crómio-cobalto e níquel-crómio menos dispendiosas, todavia exibindo adequadas propriedades mecânicas [1]. Desde então as ligas de crómio-cobalto passaram a ser utilizadas prioritariamente em próteses parciais removíveis secundariamente em coroas e pontes fixas. Um estudo efectuado em 1978, nos Estados Unidos mostrou que 29\% dos laboratórios de prótese dentária haviam aderido a estas ligas; já em 1980 e 1981 as percentagens subiram para $66 \%$ e $70 \%$, valores que se têm mantido apesar do preço do ouro ter voltado a cair substancialmente [2]. Vemos assim que desde o primeiro ensaio de utilização por volta de 1930, a sua vulgarização não tem parado, estendendo-se também ao campo dos implantes e da prótese ortopédica [1].

De acordo com a especificação n. ${ }^{ } 14$ da Associação Dentária Americana a composição destas ligas deve incluir um mínimo de $85 \%$ por peso de crómio, cobalto e níquel. O cobalto $(60 \%)$ e o crómio ( $25 \%$ a $30 \%$ ) são os componentes fundamentais; pequenas quantidades de molibdénio, carbono, tungsténio, ferro e manganésio estão habitualmente presentes como elementos endurecedores ou controladores da temperatura de fusão. $\mathrm{O}$ crómio assegura a resistência à corrosão, pela passivação da liga [3].

Os primeiros estudos retrospectivos sobre a utilização clínica destas ligas em prótese dentária, revelaram plena satisfação dos requisitos mecânicos e biológicos, apesar do elevado número de pacientes incluídos nas observações [4].

Contudo, ano após ano foram surgindo casos isolados de reacções biológicas adversas de sensibilização cutânea ou bucal aos constituintes metálicos das próteses, pondo em dúvida o conceito inicial da sua inoquidade [1-5].

Com efeito, as ligas maetálicas são imprevisivelmente sujeitas a complexos fenómenos de corrosão quando inseridas no meio bucal, em consequência das múltiplas variações de temperatura, $\mathrm{pH}$, tipo de fluxo salivar, constituição química dos alimentos ou medicamentos ingeridos, presença de bactérias e seus metabolitos. À libertação de iões metálicos, segue-se a sua absorção e passagem à corrente sanguínea $\mathrm{e}$ fixação selectiva em determinados órgãos, por períodos longos de acordo com a semi-vida desses elementos. Encon-

* Escola Superior de Medicina Dentária de Lisboa (ESMDL). 
tra-se hoje estudada por autores escandinavos a capacidade lesiva específica dos diversos metais, potencialmente capazes de desencadear fenómenos alérgicos, tóxicos, inflamatórios, após contactos mais ou menos prolongados com o organismo [1-6-7-8].

A preocupação sobre este problema acentuou-se mais na medida em que, em muitos casos as lesões não se situam na área de contacto com o metal. Tal é o caso do níquel em que as alterações da pele são mais exuberantes que as da mucosa bucal. Os sintomas subjectivos podem ser mais ou menos pronunciados consoante as condições gerais físicas ou psíquicas do paciente, tornando mais difícil o diagnóstico. Acresce ainda que as afecções de tipo alérgico não parecem depender duma relação dose-efeito, pelo que pequenas quantidades de metal libertado podem produzir graves lesões [9-10]. Estabelecida a sensibilização é difícil manter o doente afastado de futuros contactos quer com o níquel, quer com o crómio, constituintes usuais de quase todos os objectos metálicos que nos rodeiam diariamente. Fenómenos de sensibilização idênticos foram descritos em ortopedia na sequência da utilização clínica de próteses da anca em crómio cobalto.

A opinião médica dividiu-se inicialmente entre a minimização de mais um novo tipo de alergia cutânea até ao verdadeiro alarme quando se detectaram lesões cancerosas das vias respiratórias superiores em trabalhadores metalúrgicos expostos a inalação de poeiras de níquel. A prevalência neste grupo é novecentas vezes superior à da população geral. Contudo o risco de desencadear alergias de contacto é o facto dominante, estando hoje estimado que a prevalência de desmite pelo níquel é de $10 \%$ no sexo feminino e de $1 \%$ no masculino. A Suécia assume a primeira tomada de posição radical em 1974 proibindo o uso dentário de ligas contendo mais de $1 \%$ por peso de níquel, tal como já havia feito com o cádmio. Nos USA só dez anos mais tarde se verifica posição similar [2].

A situação que reportámos ilustra tipicamente um caso em que a primeira preocupação face à proposta de uso de novas ligas metálicas, se centrou na verificação imediata e exaustiva de todos os seus atributos mecânicos, físicos e químicos, negligenciando totalmente os aspectos relativos às possíveis consequências biológicas.

Há actualmente necessidade de considerar de um modo sistemático os materiais dentários como substâncias para «uso médico» tal como os fármacos, e por consequência submetê-los a bateria de testes biológicos antes de iniciar a sua utilização clínica.

Felizmente parece ser este o caminho recentemente acordado entre os representantes da indústria, dos centros de investigação e departamentos de protecção à saúde e ambiente.

\section{Referências}

[1] Bergman, B., The effects of prosthodontic materials on oral tissues. Oral Sciences Reviews, 1977, 10: 75-93.

[2] Workshop: Biocompatibility of metals in dentisty. National Institute of Dental Research. J.A.D.A., 1984, 100: 469-171.

[3] American Dental Association Specification N. ${ }^{9} 14$. Dentists' desk reference: materials, instruments and equipment. A.D.A. ed 2, 1985, pp. 93.

[4] Dooms-Goosens, A. A follow-up study of patients with contact dermatistis caused by chromates, nickel and cobalt. Dermatologia, 1980, 160: 249 260.

[5] Huget, E.F. Alternatives to gold alloys in dentistry, Dental alloys: biological considerations. Conference procedings. Valega, T.M. Sr., Ed. National Institute of Health. U.S. Department of Health. Education and Welfare, Bethesda. MD. 1977, pp. 106-138.

[6] Soremark, R. Some biological effects caused by prosthetic materials. Swed. Dent., 1979, 3: 1-7.

[7] Council of Dental Materials: Instruments and Equipament. Reportes on base metal alloys for crown and bridge application: benefits and risks. J.A.D.A., 1985, 111: 479-483.

[8] Kuhn. A.T. Corrison of $\mathrm{Co}-\mathrm{Cr}$ alloys in aqueous environements. Biomaterials, 1981, 2: 68-77.

[9] Leitão, J. Melo, F.P. Biocompatibility of cobalt-chromium alloys: in vitro and in vivo, Studies. Rev. Port. de Est. e Cir. Maxilofac., 1988, 29(4): 285296.

[10] Leitão, J. Melo, F.P. Libertação de crómio e cobalto a partir de próteses dentárias na cavidade bucal. Proccedings do I Congresso Português de Engenharia Biomédica, 1980, 60.

\title{
SOCIETÉ MÉDITERRANĖENNE DE CHIMIE
}

\author{
A Secção Regional «Languedoc-Roussillon» da Societé Française de Chimie decidiu criar uma Secção \\ Mediterrânea Internacional, com vários objectivos entre os quais se salientam: \\ - reuniōes científicas comuns sobre temas a definir; \\ - cooperação mais estreita, com troca de estudantes e de investigadores no quadro de projectos \\ europeus.
}

\author{
Para mais informações contactar: Monsieur Jacques Rouviere \\ U.S.T.L. \\ Physico-Chimie des Systèmes Polyphasés - Case 016 \\ Place Eugène Bataillon \\ 34095 Montpellier cedex 5 \\ França
}




\section{Convite à Reflexão ...}

\section{O Homem}

O Homem tem um aspecto estranho: caminha aprumado sobre duas pernas. Por isso, tem dois lados a que chama esquerda e direita. Encontrámos esta estrutura simétrico-lateral em muitos seres vivos na Terra, porém, também existe a nossa estrutura simétrico-radial, apesar de ser mais rara nos animais do que nas plantas. A imagem do mundo do Homem parece-nos muito estranha; isto deve-se talvez ao facto de ele viver o "Mundo" com os seus sentidos de uma maneira completamente diferente da nossa. Não se apercebe de algumas coisas que nós reconhecemos, mas temos de confessar que tem uma perspectiva sobre outros domínios da realidade que nós não temos. A sua "imagem do mundo" depende obviamente do facto - como já referimos atrás - de ter uma estrutura simétrico-lateral, porque "esquerda" e "direita" são partes essenciais da sua experiência do mundo e do seu modo de pensar.

Durante a nossa viagem, tivemos oportunidade de efectuar experiências com alguns homens. Os nossos testes referiam-se à assimilação temporal de estímulos. Verificámos, por exemplo, que para o Homem a simultaneidade se define de acordo com o sentido que assimila o estímulo, ou seja, na audição e na vista a simultaneidade é diferente. Mas mesmo quando reconhece os sinais como não-simultâneos, não sabe necessariamente em que sequência é que eles se deram. Neste pormenor, exprime-se de maneira muito clara a evolução atrasada do Homem.

O Homem também desenvolveu, como nós, um mecanismo que é capaz de integrar acontecimentos consecutivos em formas perceptivas. Mas esta integração tem no Homem um limite máximo de três segundos. Tudo o que se condensa dentro desse intervalo apresenta-se-lhe como consciente no presente. Para nós, foi interessante observar que o Homem só pode ter um conteúdo da consciência, enquanto em nós, devido aos princípios construtivos do nosso processador central (o Homem chama-lhe cérebro), podem decorrer paralelamente muitos processos de consciência. Esta limitação a uma consciência é uma diferença fundamental entre ele e nós. Nas nossas experiências com os Homens, este foi aliás um resultado incompreensível, durante muito tempo. Tivemos primeiro de nos libertar da nossa ideia de que é evidente ter mais do que um conteúdo da consciência.

Como o Homem só tem uma consciência num determinado momento, não é possível prever com exactidão o que é que chega à consciência. Enquanto nós evocamos consecutivamente cada consciência parcial, tendo em vista os objectivos de acção, no Homem ficam muitas vezes por esclarecer avaliações de estados de coisas, que levam à acção. O Homem chama inconsciente ao que fica por esclarecer. Portanto, o próprio Homem não sabe muitas vezes por que é que se lembra de determinada coisa ou por que é que faz uma coisa determinada. Encontra-se, num certo sentido, entregue a si próprio, o que ocasiona muitas vezes problemas na sua relação com os outros homens. $\mathrm{O}$ que chega à sua consciência está sempre colorido pelos sentimentos, o que leva a que os seus actos sejam sempre influenciados pelas suas emoções; pelo contrário, os nossos actos decorrem a um nível puramente racional, podendo ser por isso continuamente controlados e efectivamente por nós controlados. Mas, visto que nem sempre tem consciência das suas emoções, o seu comportamento desperta muitas vezes uma im- pressão descontrolada e irracional em quem está de fora. Foi uma surpresa para nós observar que a vida social do Homem não parece ser possível, segundo critérios puramente racionais. No decurso ela evolução, desenvolveram-se no cérebro do Homem inúmeras estruturas que são responsáveis pela compreensão da realidade. Cada estrutura parcial, também the podemos chamar módulo, é responsável por uma determinada categoria; podemos nomear uma muito simples, por exemplo, a categoria "cor". Para nós, foi interessantíssimo observar o número reduzido destas categorias. Visto que a "imagem do mundo" do Homem se apoia na compreensão categorial da realidade, é lógico que a visão humana do mundo também seja limitada. O Homem nem sequer faz a mínima ideia de que a realidade em que vive é muito mais extensa, e isto apenas porque lhe faltam as categorias necessárias, devido às condições evolutivas preliminares. As observações que fizemos no Homem ajudaram-nos, todavia, a pôr a seguinte questão: é possível que a nossa própria realidade também seja limitada apesar de ser mais vasta do que a do Homem na Terra, devido ao maior número de categorias?

O Homem, porém, desenvolveu um modo de proceder bastante interessante para the permitir alargar os limites da sua visão do mundo, que the foi imposta pela sua própria evolução. Ele chama Ciência a este modo de proceder. Examina outros seres vivos-do mesmo modo que nós o examinámos a ele - e, a partir do estudo da realidade desses seres vivos, consegue ter uma visão mais vasta da natureza. Porém, esta visão não é uma vivência imediata, mas uma deduçâo mediata com base nas observações efectuadas; é preciso dizer que, com este método, ele teve um grande sucesso. A adaptação evolutiva de outros seres vivos informou-o sobre uma realidade mais vasta, mas afinal naturalmente oculta. Assim, reconhece pelo menos que a sua própria realidade não é absoluta, mas apenas uma imagem condicionada pela sua evolução.

Todavia, duvida-se de que ele tenha, no fim de contas, sucesso com esta tentativa de expansão da realidade. $\hat{E}$ que os seus órgãos pensantes também dependem, muito naturalmente, das condições evolutivas, ou seja, das categorias de que dispõe, e segundo as quais descreve o Mundo. Os conceitos não são independentes das categorias criadas; o conceito "com-preensão", muito generalizado no Homem, exprime isto muito lucidamente. Por isso, a experiência do mundo do Homem é afinal circular, quer dizer: gira num círculo, porque só se pode compreender aquilo para que há categorias. A sua realidade tem de ser obrigatoriamente uma construção com base nos mecanis. mos cerebrais que lhe foram postos à disposição. $\mathrm{O}$ Homem não pode sair de si próprio e observar-se do exterior.

A visita a este satélite solar proporcionou-nos uma nova visão interessante sobre uma espécie agora descoberta. Para nós, tornou-se sobretudo evidente que, sem os limites da consciência - como os observámos no Homem -, ele não teria à sua disposição nenhuma realidade. As fronteiras definem o quadro formal, para que a realidade possa de todo compreender-se. Sem limites só existiria o caos para o Homem. Visto que as observações sobre a possibilidade limitada de o Homem construir uma realidade foram tão instrutivas, temos de admitir que a nossa própria realidade também é limitada. Devíamos pensar nisso... 


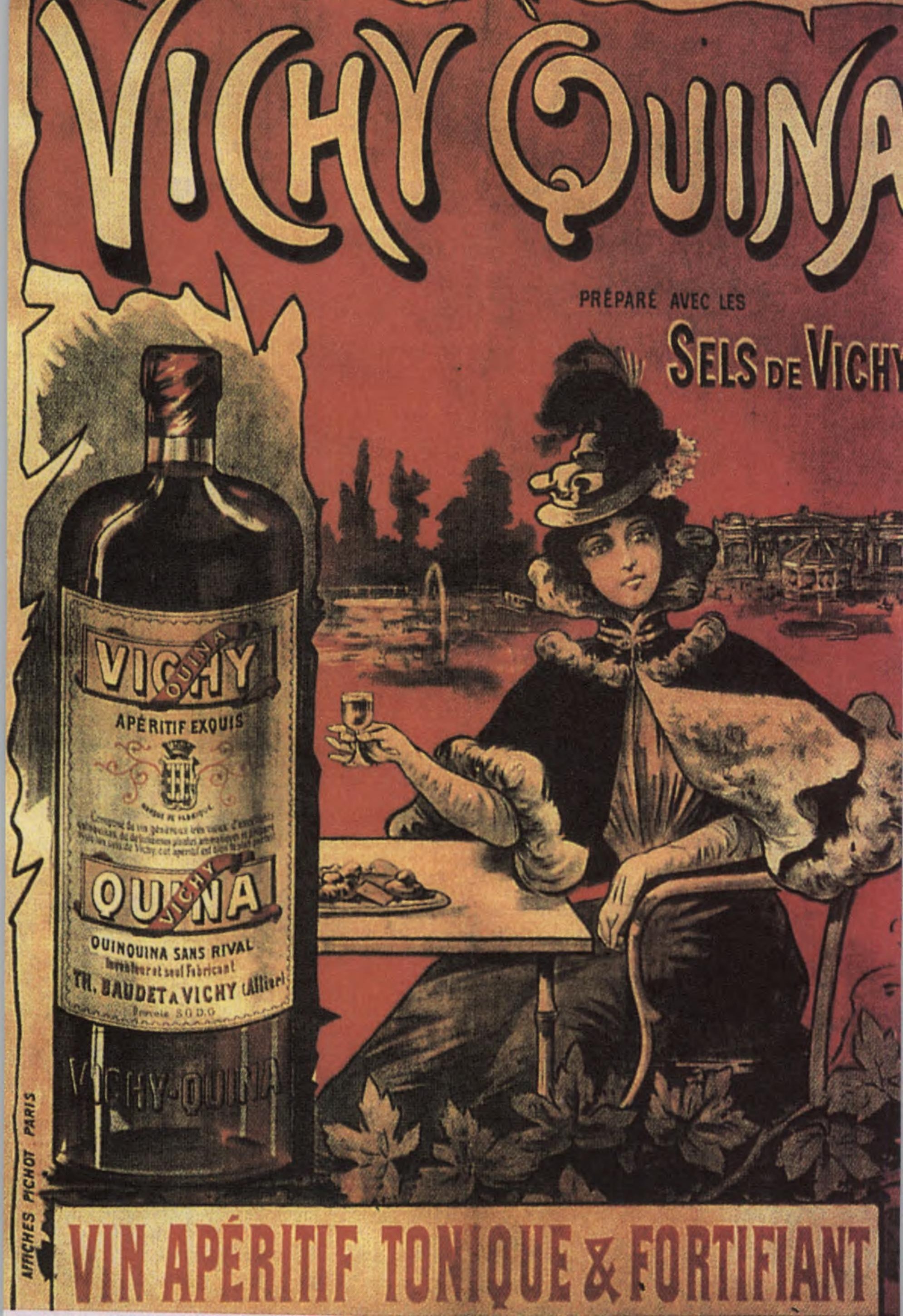

